\title{
Preços Hedônicos no Mercado Imobiliário Comercial de São Paulo: A Abordagem da Modelagem Multínível com Classificação Cruzada
}

\author{
Luiz Paulo Lopes Fávero
}

Submetido: 04 de fevereiro de 2010; aceito para publicação: 21 de outubro de 2010

Resumo: Os modelos de preços hedônicos frequentemente não levam em consideração a natureza hierárquica com classificação cruzada existente no mercado de aluguel de escritórios. Este artigo emprega um modelo multinível com classificação cruzada (HCM2), com o intuito de examinar a influência das características dos imóveis, dos distritos e das zonas comerciais sobre os preços de aluguel em São Paulo. Por meio de uma amostra com 277 imóveis provenientes de 15 distritos em classificação cruzada com 10 zonas comerciais, encontra-se representatividade das características das propriedades, dos distritos e das zonas comerciais, em caráter multinível, para a diferenciação das médias dos preços de aluguel dos imóveis no ano de 2008.

Palavras-Chave: preços de aluguel de escritórios, preços hedônicos, modelos multinível com classificação cruzada (HCM2), modelos hierárquicos lineares (HLM)

Abstract: Hedonic pricing models often don't take into account the cross-classified hierarchical nature of the office rental markets. This paper employs a cross-classified multilevel model (HCM2) to examine the impact that office characteristics, district and commercial zones have on rental prices in São Paulo. Using a sample of 277 properties from 15 districts cross-classified with 10 commercial

Agradeço os Professores Doutores Thomas J. Trebat, Gilberto de Andrade Martins, Linda Lee Ho, Denise Botter e Lucia Pereira Barroso pelas importantes contribuições quando da elaboração e defesa da Tese de Livre-Docência, em que parte da pesquisa resultou neste artigo. Agradeço também aos anônimos pareceristas pelas valiosas sugestões. Naturalmente, erros e omissões remanescentes são de minha inteira responsabilidade.

Luiz Paulo Lopes Fávero

Professor Livre-Docente - Departamento de Contabilidade e Atuária da Faculdade de Economia, Administração e Contabilidade da USP - Endereço para contato: Av. Prof. Luciano Gualberto, 908 FEA 3, sala 211 - CEP: 05508-010 - Cidade Universitária - São Paulo - E-mail: 1pfavero@usp.br 
zones, multilevel representativeness is found for the effects of the properties', districts' and zones' characteristics, considering the differentiation of mean prices in 2008.

Keywords: office rental prices, hedonic prices, cross-classified multilevel models (HCM2), hierarchical linear models (HLM)

\section{JEL Classification: C5}

\section{Introdução}

A definição da estrutura de preços do mercado imobiliário tem sido estudada a partir de modelos que estimam o preço de aluguel de uma determinada unidade comercial pelos atributos por ela apresentadas (Leeuw, 1993), e não única e exclusivamente pelo custo da construção. De acordo com Brown e Uyar (2004), a grande maioria dos modelos hedônicos de regressão aplicados à avaliação imobiliária tradicionalmente apresentam, como variável dependente, o preço do imóvel e, como variáveis explicativas, os vários atributos intrínsecos e extrínsecos aos imóveis que determinam a importância de determinadas características para a formação deste preço, como apontam os trabalhos de Palmquist (1984), Yinger, Bloom, Borsch-Supan e Ladd (1988), Cheshire e Sheppard (1998), Downes e Zabel (2002) e Paterson e Boyle (2002). Porém, como os imóveis estão localizados em vizinhanças, estas em municípios e, assim por diante, as decisões de locação de um determinado imóvel comercial são inerentemente hierárquicas, ou seja, em estágios. Como descreve Quigley (1985) e Moreira (1997), os potenciais locatários iniciam o seu processo de procura do imóvel desejado escolhendo primeiramente o município, seguido pela vizinhança (zona ou distrito dentro do município escolhido) e, finalmente, o imóvel propriamente dito, naquele específico distrito dentro do município definido anteriormente.

Os modelos hedônicos tradicionais de regressão, entretanto, não conseguem capturar estes efeitos e adquirir alguma vantagem da hierarquia natural dos dados quando da modelagem de preços no mercado imobiliário. Como as unidades imobiliárias situadas, por exemplo, em uma determinada vizinhança, compartilham aspectos sociodemográficos e amenidades urbanas daquela localidade, e como 
esta vizinhança representa um nível na hierarquia de análise, estes imóveis tendem a ser mais similares entre si em comparação a todos os outros que fazem parte das demais vizinhanças do município e, portanto, a hierarquia dos dados viola a premissa de independência entre as observações, o que faz com que métodos hedônicos tradicionais de avaliação imobiliária que utilizam estimadores de mínimos quadrados ordinários (OLS) em equações de um único nível, por exemplo, gerem resultados duvidosos e inconsistentes, uma vez que oferecem vieses nos estimadores por não levarem em consideração os efeitos do ambiente hierárquico inerente a estes mercados. Portanto, a principal vantagem da modelagem hierárquica é que esta consegue explicitamente corrigir o problema de hierarquia natural dos dados.

Uma abordagem alternativa, por vezes utilizada na literatura relativa ao mercado imobiliário, refere-se à aplicação de modelos logísticos multinomiais (McFadden, 1978), que levam em consideração um processo discreto de escolha dos potenciais locatários de imóveis por meio da identificação da importância de diversos atributos e que conseguem capturar a hierarquia inerente aos dados, o que está de acordo com os procedimentos adotados por Quigley (1985), Nechyba e Strauss (1998) e Chattopadhyay (2000). Por outro lado, esta abordagem não tem como objetivo explicar os preços dos imóveis, mas examinar a influência de cada atributo na probabilidade de aquisição de cada imóvel (Brown e Uyar, 2004).

A abordagem da Modelagem Hierárquica Linear (HLM) pode ser empregada sob uma perspectiva hedônica para a avaliação dos preços de imóveis, como já fazem os modelos hedônicos tradicionais de regressão com limitações e, ao mesmo tempo, incorporar na análise a natureza hierárquica dos dados, como fazem os modelos logísticos multinomiais (Brown e Uyar, 2004).

Segundo Uyar e Brown (2007), os imóveis estão localizados em quarteirões, distritos, zonas, unidades censitárias, entre outras unidades urbanas, que definem agrupamentos hierárquicos que nem sempre apresentam um perfeito aninhamento, já que as classificações não estão dispostas segundo uma hierarquia funcional mutuamente excludente, ou seja, nem todos os imóveis pertencentes a um determinado distrito estão localizados na mesma zona e, da mesma forma, nem todos pertencentes à mesma zona localizam-se no mesmo distrito. 
Esta classificação cruzada espacial, frequente no mercado imobiliário, nem sempre é levada em consideração em modelos hedônicos e pode ser investigada por meio dos modelos multinível com classificação cruzada (HCM2).

Os modelos multinível permitem, por exemplo, que imóveis que se situam em diferentes localidades possam apresentar diferentes preços de aluguel, que também podem ser diferentes daqueles localizados na mesma vizinhança. Este estudo espera contribuir para a discussão acerca da formação de preços no mercado imobiliário e como estes são influenciados por características dos imóveis e das localidades do entorno. Como as localidades consideradas sobrepõemse geograficamente, são consideradas hierarquias com classificação cruzada por meio de um modelo HCM2, que propicia a análise do impacto das diferenças nas características entre distritos e entre zonas comerciais sobre os preços de aluguel e torna possível o estudo das inter-relações das características dos distritos e das zonas comerciais para a formação dos preços. Ressalte-se que não se conhece, até o presente momento e de acordo com a pesquisa realizada para a elaboração do presente estudo, trabalhos que utilizem modelagem multinível com classificação cruzada para a avaliação de imóveis comerciais sob o enfoque de preços hedônicos de aluguel.

Na seção 2 será apresentada a revisão da literatura, com ênfase para os trabalhos que trazem aplicações de modelagem hierárquica. A seção 3 apresenta analiticamente a modelagem multinível com classificação cruzada. Enquanto a seção 4 oferece subsídios à utilização da modelagem multinível com classificação cruzada, por meio da apresentação das regiões geográficas, da caracterização da amostra e da definição das variáveis, a seção 5 destina-se à apresentação dos resultados. Por fim, as conclusões e possíveis extensões são discutidas na seção 6 .

\section{Revisão da Literatura}

A utilização de modelos hedônicos na determinação de valores das propriedades imobiliárias é bem documentada. Muitos autores efetuaram estudos sobre a utilização da abordagem de preços hedônicos por meio de modelos clássicos de regressão, como Megbolugbe (1989), Aryeetey-Attoh (1992), Mills (1992), Clark e Herrin (2000), 
Chau, Ma e Ho (2001), Bible e Hsieh (2001), Leishman (2001), Strand e Vagnes (2001), Figlio e Lucas (2004), Simons e Jaouhari (2004) e Anselin e Gracia (2008). Esta abordagem, mais comumente aplicada no mercado imobiliário residencial e conhecida por abordagem de Court-Griliches-Lancaster, trata da utilização de modelos que aplicam uma única equação hedônica, seja de oferta ou de demanda, para a avaliação dos preços de imóveis pela presença de atributos associados a eles.

A abordagem de Rosen (1974), por outro lado, vem como crítica à utilizada por Court-Griliches-Lancaster, já que esta não levava em consideração a endogeneidade dos modelos, e propõe uma expansão dos conceitos por meio da definição de equações de oferta e demanda, com o intuito de ser possível a determinação do equilíbrio de mercado. É necessário destacar que o método proposto por Rosen (1974) também sofreu várias críticas de diversos autores que se propuseram a estudar as formas de precificação hedônica, entre os quais Palmquist (1984) e Bartik (1987), que afirmam que o problema de estimação hedônica deve-se à existência de endogeneidade presente nas variáveis consideradas nos modelos.

As abordagens de Court-Griliches-Lancaster e de Rosen sofrem, portanto, algumas limitações, que se referem à ausência de cuidados apropriados com os estimadores dos modelos, dada a consideração de atributos intrínsecos e extrínsecos no mesmo nível da equação. Ademais, a abordagem de Rosen ainda falha ao considerar o pressuposto de que não há nenhuma inter-relação entre o preço de cada uma das variáveis explicativas que correspondem aos atributos (Ekeland, Heckman e Nesheim, 2002).

A fim de facilitar o entendimento de como se comportam isoladamente os atributos intrínsecos e extrínsecos e os seus componentes de variância para a valorização dos preços de aluguel de imóveis comerciais no Município de São Paulo, o presente estudo opta pela utilização de modelos hedônicos em caráter multinível aplicados a dados de imóveis localizados em regiões específicas, e não pelo uso de um modelo de equações de nível único. Em comparação com os modelos clássicos de regressão linear ou de análise de covariância, os modelos multinível apresentam a vantagem de levar em consideração a análise de dados hierarquicamente estruturados. Estes modelos propõem uma estrutura de análise dentro da qual podem ser reco- 
nhecidos os distintos níveis em que se articulam os dados, estando cada subnível representado pelo seu próprio submodelo (Draper, 1995). Cada um desses submodelos, de acordo com Soto e Morera (2005), expressam a relação entre as variáveis dentro de um determinado nível e especificam como as variáveis deste nível influenciam as relações que se estabelecem em outros níveis.

Raudenbush e Bryk (2002) discutem as aplicações da modelagem multinível em várias áreas do conhecimento, particularmente em educação, em que podem ser citados os trabalhos de Aitkin, Anderson e Hinde (1981), Aitkin e Longford (1986), Raudenbush e Bryk (1986), Garner e Raudenbush (1991), Raudenbush (1993), Rumberger e Thomas (1993), Osborne (2000), Goldstein (2003), O’Donnell e McCoach (2008) e Xu (2008).

Merecem ainda destaque os trabalhos de Jones, Johnston e Pattie (1992) sobre os efeitos multinível de pessoas, localidades e regiões sobre os dados eleitorais, de Kahane (2001) sobre economia do esporte e a importância dos atributos de jogadores e de suas respectivas equipes para a explicação da evolução de seus salários, de Sibthorp, Witter, Wells, Ellis e Voelk1 (2004) sobre a economia do turismo, de Bottai, Salvati e Orsini (2006) sobre o comportamento diário das movimentações das pessoas, e de Mithas, Ramasubbu, Krishnan e Fornell (2007) sobre a lealdade de consumidores em compras pela internet.

Modelagens multinível, por vezes sem a presença de classificação cruzada, são extensivamente utilizadas na literatura sobre estratégia para comparar variâncias existentes nos níveis de firma e de segmento para a composição do desempenho de empresas. Nesta linha, merecem destaque os trabalhos de Schmalensee (1985), Mauri e Michaels (1998), Chang e Singh (2000), Cardoso (2000), Ruefli e Wiggins (2003) e Short, Ketchen Jr., Palmer e Hult (2007). Outros autores têm analisado o efeito país de origem sobre o desempenho das firmas, merecendo destaque os trabalhos de Collins (1990), Christmann, Day e Yip (1999), Lee (2003), Hawawini, Subramanian e Verdin (2004), Makino, Isobe e Chan (2004), Makino, Beamish e Zhao (2004) e Goldszmidt, Brito e Vasconcelos (2007). Outros ainda têm estudado o efeito município, ou micro-localidade, para avaliação de determinados fenômenos em pessoas ou empresas, como Price, Nero e Gelman (1996) e Gelman (2006). 
Porém, a utilização de modelagem multinível aplicada à avaliação de imóveis, sob uma perspectiva hedônica, ainda é incipiente, merecendo destaque os trabalhos pioneiros de Jones e Bullen (1994), de Goodman e Thibodeau (1998), de Gelfand, Ghosh, Knight e Sirmans (1998), e de Brown e Uyar (2004) aplicados ao mercado imobiliário residencial. O estudo de Uyar e Brown (2007) é seminal por utilizar um modelo multinível com classificação cruzada para analisar o impacto que diferenças em vizinhanças e em zonas escolares têm na valoração das características de imóveis residenciais e em seus respectivos preços.

Numa perspectiva temporal, o trabalho de Fávero e Belfiore (2008) também elabora uma análise hierárquica, com a caracterização de três níveis para a formação de preços (nível 1: medida repetida; nível 2: imóveis; nível 3: distritos municipais), porém com aplicação ao mercado imobiliário residencial. Ainda sob uma perspectiva hedônica e com a utilização de modelos hierárquicos lineares, merece ainda destaque o trabalho de Rengers e Velthuis (2002) sobre a avaliação dos preços de obras de arte na Holanda em função dos atributos do objeto, como dimensões e material (nível 1), de características do artista como idade, sexo, local de residência e reconhecimento institucional (nível 2), e dos aspectos relativos à galeria em que está exposta a obra, como localidade, afiliação institucional e idade (nível 3).

No Brasil, o mercado imobiliário é razoavelmente estudado sob a perspectiva hedônica, porém por meio de métodos tradicionais (Dantas e Cordeiro, 1988; Barbosa e Bidurin, 1991; Aryeetey-Attoh, 1992; González e Formoso, 1994; Hermann, 2005; e Fávero, Belfiore e Lima, 2008). Recentemente, Fávero e Belfiore (2008), por outro lado, aplicaram métodos multinível com medidas repetidas para avaliar a evolução dos preços de unidades residenciais em São Paulo, por meio da utilização de modelos de formação de preços em três níveis (nível 1: medida repetida; nível 2: características dos imóveis; nível 3: características dos distritos municipais).

O presente trabalho é baseado na lógica proposta por Uyar e Brown (2007), porém difere-se daquele em termos dos vetores de variáveis intrínsecas e extrínsecas e dos critérios por meio dos quais foram definidos os espaços urbanos, uma vez que, naquele trabalho, o objeto de estudo era o mercado imobiliário residencial. No presente artigo, as variáveis foram definidas por especialistas por meio de 
um levantamento autoadministrado com a intenção de investigar as influências que podem eventualmente explicar os preços de aluguel dos escritórios em São Paulo. Ao contrário de Uyar e Brown (2007), que utilizaram somente uma variável em cada nível hierárquico de localidade (vizinhança e zonas escolares), este estudo inicialmente considera diferentes variáveis para cada um dos níveis de localidade (distrito e zona comercial).

\section{Modelagem Multinível com Classificação Cruzada (HCM2)}

Nos modelos HCM2, de acordo com Uyar e Brown (2007), cada uma das hierarquias é representada por seu próprio submodelo. Estes submodelos podem ser utilizados para testar a significância estatística das várias interações da classificação cruzada hierárquica. Assim, estes modelos podem assumir várias formas, dependendo do número de hierarquias presentes nos dados, do que o pesquisador está interessado em testar, se os submodelos apresentam variáveis explicativas e se estes submodelos levam em consideração os efeitos aleatórios.

A análise hierárquica com classificação cruzada, seguindo Raudenbush e Bryk (2002), permite que sejam alcançados os seguintes objetivos:

- estimação dos componentes de variância dos preços de aluguel entre distritos, entre zonas comerciais e entre imóveis ("dentro" das células distrito-zona);

- identificação de características de distritos e zonas comerciais associadas com os preços de aluguel dos imóveis;

- estimação dos componentes de variação residual nos preços de aluguel entre distritos, entre zonas e "dentro" das células após a consideração das características dos imóveis, dos distritos e das zonas comerciais;

- avaliar em que medida as associações entre as características dos imóveis e seus preços de aluguel variam entre distritos, zonas e células;

- avaliar em que medida as características dos distritos apresentam efeitos que variam entre zonas e em que medida estas têm características que variam entre distritos; 
- estimação dos efeitos aleatórios associados com distritos ou zonas comerciais.

\subsection{Modelo Não Condicional}

Em modelos HCM2, de acordo com a tabela de classificação cruzada (Tabela 1 apresentada na seção 4), a estimação dos componentes de variância entre distritos, entre zonas comerciais e "dentro" das células é elaborada por meio do modelo não condicional, que não considera a inclusão de variáveis preditoras em qualquer nível da análise (Raudenbush e Bryk, 2002).

Nível 1 (Modelo "Dentro" da Célula): Um único vetor de imóveis é aninhado "dentro" de cada célula da classificação cruzada e, portanto, este modelo descreve a variância entre imóveis. Assim:

$$
\ln \left(\text { preço }_{i j k}=\pi_{0 j k}+e_{i j k}, e_{i j k} \sim \mathrm{N}\left(0, \sigma^{2}\right),\right.
$$

em que:

- $\ln (\text { preço })_{\mathrm{ijk}}$ é o preço de aluguel do imóvel i do distrito j e na zona comercial k;

- $\pi_{0 \mathrm{jk}}$ é a média do preço de aluguel dos imóveis na célula jk, isto é, imóveis localizados no distrito $\mathrm{j}$ e na zona $\mathrm{k}$;

- e e é o "efeito imóvel" aleatório, isto é, o desvio do preço do imóvel ijk em relação à média da célula. Assume-se que estes desvios são normalmente distribuídos com média 0 e variância $\sigma^{2}$ "dentro" da célula.

Os subscritos $\mathrm{i}$, j e k representam, respectivamente, os imóveis, os distritos e as zonas comerciais, de modo que:

- $\mathrm{i}=1, \ldots, \mathrm{n}_{\mathrm{jk}}$ imóveis de célula jk;

$-\mathrm{j}=1, \ldots, \mathrm{J}=15$ distritos municipais;

$-\mathrm{k}=1, \ldots, \mathrm{K}=10$ zonas comerciais.

Nível 2 (Modelo "Entre" Células): A variação entre células é atribuída aos efeitos dos distritos, das zonas comerciais e, possivelmente, aos efeitos da interação distrito-zona. Desta forma: 


$$
\begin{gathered}
\pi_{0 j k}=\theta_{0}+b_{00 j}+c_{00 k}+d_{0 j k}, \\
\mathrm{~b}_{00 \mathrm{j}} \sim \mathrm{N}\left(0, \tau_{\mathfrak{b}}\right) ; \mathrm{c}_{00 \mathrm{k}} \sim \mathrm{N}\left(0, \tau_{\tilde{c}}\right) ; \mathrm{d}_{0 \mathrm{jk}} \sim \mathrm{N}\left(0, \tau_{\tilde{\mathrm{d}}}\right),
\end{gathered}
$$

em que:

- $\theta_{0}$ é a média geral dos preços de aluguel para todos os imóveis;

- $b_{00 j}$ é o efeito aleatório principal do distrito j, isto é, a contribuição do distrito $\mathrm{j}$ sobre todas as zonas (assume-se que é normalmente distribuído com média 0 e variância $\left.\tau_{\mathfrak{b}}\right)$;

- cook é o efeito aleatório principal da zona comercial k, isto é, a contribuição da zona $\mathrm{k}$ sobre todos os distritos (assume-se que é normalmente distribuído com média 0 e variância $\tau_{\tilde{c}}$ );

- $\mathrm{d}_{0 \mathrm{jk}}$ é o efeito aleatório da interação, isto é, o desvio da média da célula em relação ao predito pela média geral e pelos dois efeitos principais (assume-se que é normalmente distribuído com média 0 e variância $\left.\tau_{\tilde{d}}\right)$.

Ainda, seguindo Raudenbush e Bryk (2002), tem-se que o modelo não condicional mesclado (unconditional mixed model) é definido pela substituição de (2) em (1), de modo que:

$$
\ln (\text { preço })_{i j k}=\theta_{0}+b_{00 j}+c_{00 k}+d_{0 j k}+e_{i j k}
$$

que é conhecido por modelo de análise de variância em duas dimensões com efeitos aleatórios em linha $b_{00 j}$, efeitos aleatórios em coluna $\mathrm{c}_{00 \mathrm{k}}$, interação em duas dimensões $\mathrm{d}_{0 \mathrm{jk}}$ e desvios "dentro" da célula $e_{\mathrm{ijk}}$.

Os modelos de dois níveis HCM2 descritos por meio das expressões (1) e (2) decompóem a variância dos preços de aluguel em um componente dentro das células (within-cell) $\left(\sigma^{2}\right)$ e um componente entre células (between-cell). Este último componente é ainda decomposto em três novos componentes: variância entre distritos ( $\left.\tau_{\bar{b}}\right)$, variância entre zonas comerciais $\left(\tau_{\tilde{c}}\right)$ e variância residual entre células, ou seja, variância entre células que não são consideradas pelas variâncias das linhas e das colunas $\left(\tau_{d}\right)$ : Isto propicia a elaboração de três coeficientes de correlação intraclasse, a saber: 


$$
\operatorname{corr}\left(Y_{i j k}, Y_{i^{\prime} j k}\right)=\rho_{b c d}=\frac{\tau_{b 00}+\tau_{c 00}+\tau_{d 00}}{\tau_{b 00}+\tau_{c 00}+\tau_{d 00}+\sigma^{2}}
$$

que mede a correlação entre preços de aluguel de imóveis que se localizam no mesmo distrito e na mesma zona comercial (correlação intracélula);

$$
\operatorname{corr}\left(Y_{i j k}, Y_{i^{\prime} k^{\prime}}\right)=\rho_{b}=\frac{\tau_{b 00}}{\tau_{b 00}+\tau_{c 00}+\tau_{d 00}+\sigma^{2}}
$$

que mede a correlação entre preços de aluguel de imóveis que se localizam no mesmo distrito (correlação "intradistrito"), porém em zonas comerciais diferentes;

$$
\operatorname{corr}\left(Y_{i j k}, Y_{i^{\prime} j^{\prime} k}\right)=\rho_{c}=\frac{\tau_{c 00}}{\tau_{b 00}+\tau_{c 00}+\tau_{d 00}+\sigma^{2}}
$$

que mede a correlação entre preços de aluguel de imóveis que se localizam na mesma zona comercial (correlação intrazona), porém em distritos diferentes.

\subsection{Modelo Condicional}

Já que o modelo não condicional completo (fully unconditional model) HCM2 especifica a variabilidade associada com imóveis, distritos e zonas comerciais, presumidamente parte desta variabilidade pode ser devida às variáveis preditoras relacionadas às características dos imóveis, dos distritos e das zonas comerciais, bem como às próprias interações relevantes entre elas.

Dessa forma, o modelo aleatório geral com classificação cruzada consiste de dois submodelos: nível 1, ou modelo dentro da célula; e nível 2 , ou modelo entre as células. As células referem-se às classificações cruzadas pelas unidades de mais alto nível. Formalmente, há $i=1$, $2, \ldots, n_{\mathrm{jk}}$ propriedades de nível 1 aninhadas dentro de células classificadas (classificação cruzada) por $\mathrm{j}=1,2, \ldots, \mathrm{J}$ distritos de nível 2, 
designados por linhas, e $\mathrm{k}=1,2, \ldots, \mathrm{K}$ zonas comerciais de nível 2, designadas por colunas.

O nível 1, ou modelo dentro da célula, o preço de aluguel da propriedade i em uma célula individual classificada pelas unidades do nível $2 \mathrm{j}$ e $\mathrm{k}$, e podem ser escritas como:

$$
\ln \left(\text { preço }_{i j k}=\pi_{0 j k}+\sum_{p=1}^{P} \pi_{p j k} a_{p i j k}+e_{i j k}\right.
$$

em que:

- $\pi_{\mathrm{pjk}}(\mathrm{p}=1,2, \ldots, \mathrm{P})$ são os coeficientes do nível 1 ;

- $a_{\mathrm{pijk}}$ é a variável preditora p do nível 1 para o caso i na célula jk;

- $e_{\mathrm{ijk}}$ é o efeito de nível 1 ou efeito aleatório dentro da célula;

- $\sigma^{2}$ é a variância de $\mathrm{e}_{\mathrm{ijk}}$, ou seja, a variância de nível 1 ou variância dentro da célula, assumindo que o termo aleatório $\mathrm{e}_{\mathrm{ijk}} \sim \mathrm{N}\left(0, \sigma^{2}\right)$.

Cada um dos coeficientes $\pi_{\mathrm{pjk}}$ de nível 1 (ou coeficientes do modelo dentro da célula), de acordo com Raudenbush, Bryk, Cheong, Congdon e du Toit (2004), tornam-se uma variável dependente no nível 2, ou modelo entre células, como segue:

$$
\begin{aligned}
& \pi_{p j k}=\theta_{p}+\left(\beta_{p 1}+b_{p 1 j}\right) X_{1 k}+\left(\beta_{p 2}+b_{p 2 j}\right) X_{2 k}+\ldots+\left(\beta_{p Q_{p}}+b_{p Q_{p} j}\right) X_{Q_{p} k}+ \\
& \left(\gamma_{p 1}+c_{p 1 k}\right) W_{1 j}+\left(\gamma_{p 2}+c_{p 2 k}\right) W_{2 j}+\ldots+\left(\gamma_{p R_{p}}+c_{p R_{p} k}\right) W_{R_{p} j}+ \\
& \delta_{p 1 j k} Z_{1 j k}+\delta_{p 2 j k} Z_{2 j k} \ldots+\delta_{p S_{p} j k} Z_{S_{p} j k}+b_{p 0 j}+c_{p 0 k}+d_{p 0 j k} \\
& \pi_{p j k}=\theta_{p}+\sum_{q=1}^{Q_{p}}\left(\beta_{p q}+b_{p q j}\right) X_{q k}+\sum_{r=1}^{R_{p}}\left(\gamma_{p r}+c_{p r k}\right) W_{r j}+\sum_{s=1}^{S_{p}} \delta_{p s j k} Z_{s j k}+b_{p 0 j}+c_{p 0 k}+d_{p 0 j k}
\end{aligned}
$$

em que:

- $\theta_{\mathrm{p} 00}$ é o intercepto do modelo, o valor esperado de $\pi_{\mathrm{pjk}}$ quando todas as variáveis explicativas são 0 ; 
- $\beta_{\mathrm{pq}}$ são os efeitos fixos das variáveis preditoras de coluna $\mathrm{X}_{\mathrm{qk}}, \mathrm{q}=$ $1,2, \ldots, Q_{p}$;

- $b_{\mathrm{pqj}}$ são os efeitos aleatórios associados com as variáveis preditoras de coluna $X_{\mathrm{qk}}$ e variam aleatoriamente entre as linhas $\mathrm{j}=1,2, \ldots$, $\mathrm{J}$;

- $\gamma_{\mathrm{pr}}$ são os efeitos fixos das variáveis preditoras de linha $\mathrm{W}_{\mathrm{r} j}, \mathrm{r}=1$, $2, \ldots, \mathrm{R}_{\mathrm{p}}$;

- C prk são os efeitos aleatórios associados com as variáveis preditoras de linha $\mathrm{W}_{\mathrm{rj}}$;

- $\delta_{\mathrm{psjk}}$ são os efeitos fixos das variáveis preditoras de cada célula $Z_{\mathrm{sjk}}$, os quais representam os termos de interação criados pelo produto de $\mathrm{X}_{\mathrm{qk}}$ por $\mathrm{W}_{\mathrm{r} j}, \mathrm{~s}=1,2, \ldots, \mathrm{S}_{\mathrm{p}}$ e $\mathrm{S}_{\mathrm{p}} \leq \mathrm{R}_{\mathrm{p}} \times \mathrm{Q}_{\mathrm{p}}$;

- $b_{\mathrm{p} 0 \mathrm{j}}, \mathrm{c}_{\mathrm{p} 0 \mathrm{k}}, \mathrm{d}_{\mathrm{p} 0 \mathrm{jk}}$ são os efeitos aleatórios dos resíduos de linha, coluna e células, respectivamente, sobre $\pi_{\mathrm{pjk}}$, após levar em consideração os efeitos de $\mathrm{X}_{\mathrm{qk}}, \mathrm{W}_{\mathrm{rj},}$, e $Z_{\mathrm{sj} \mathrm{k}}$. Assume-se que $\mathrm{b}_{\mathrm{p} 0 \mathrm{j}} \sim \mathrm{N}\left(0, \tau_{\mathrm{pb} 00}\right), \mathrm{c}_{\mathrm{p} 0 \mathrm{k}} \sim$ $\mathrm{N}\left(0, \tau_{\mathrm{pc} 00}\right)$, e que os efeitos são independentes entre si.

Assume-se ainda que o vetor que contém os elementos $b_{\text {pqj }}$ apresenta distribuição normal multivariada com média 0 e matriz de covariância $\tau$. Similarmente, assume-se que o vetor com os elementos $c_{p r k}$ apresenta distribuição normal multivariada com média 0 e matriz de covariância $\Delta$.

A fim de facilitar a exposição do modelo condicional combinado (combined conditional model) assume-se, apenas neste momento, que há somente uma única variável de distrito $\left(\mathrm{W}_{\mathrm{j}}\right)$, uma única variável de zona comercial $\left(X_{k}\right)$ e uma variável de interação $\left(Z_{j k}=\right.$ $\mathrm{W}_{\mathrm{j}}{ }^{*} \mathrm{X}_{\mathrm{k}}$ ). Assim, substituindo (8) em (7), para $\mathrm{p}=0$ e 1 , seguindo Uyar e Brown (2007), tem-se que o seguinte modelo condicional combinado:

$\ln (\text { preço })_{i j k}=\theta_{0}+\beta_{0} X_{k}+b_{01 j} X_{k}+\gamma_{0} W_{j}+c_{01 k} W_{j}+\delta_{0}\left(Z_{j k}\right)+$ $\theta_{1} a_{i j k}+\beta_{1}\left(X_{k} * a_{i j k}\right)+b_{11 j}\left(X_{k} * a_{i j k}\right)+\gamma_{1}\left(W_{j} * a_{i j k}\right)+c_{11 k}\left(W_{j} * a_{i j k}\right)+\delta_{1}\left(Z_{j k} * a_{i j k}\right)+$ $b_{10 j} a_{i j k}+c_{10 k} a_{i j k}+d_{1 j k} a_{i j k}+b_{00 j}+c_{00 k}+d_{0 j k}+e_{i j k}$

Nota-se que a expressão (9) apresenta dois níveis e serve para ilustrar a especificação nível por nível do modelo condicional em um HCM2. Assim, cada propriedade imobiliária é avaliada segundo duas 
vertentes (distritos e zonas comerciais) e, neste caso, por meio da estimação dos coeficientes de quatro variáveis preditoras, incluindo $Z_{\mathrm{jk}}$. O número total de coeficientes e resíduos que precisam ser estimados na Equação (9) é 19 e quanto mais variáveis são adicionadas em ambos os níveis, a equação torna-se mais complexa, e o número de resíduos a ser estimado aumenta drasticamente.

De acordo com Uyar e Brown (2007), uma maneira de levar em consideração este fenômeno é determinar quais variáveis preditoras em cada nível são mais propensas a ter efeitos fixos em vez de aleatórios, e isto deve ser considerado quando o modelo condicional é estimado. Outra maneira é fazer com que os efeitos aleatórios da interação "distrito-por-zona" $\left(\mathrm{d}_{0 \mathrm{jk}}\right)$ sejam iguais a 0 , conforme será apresentado na seção 5 .

\section{Caracterização da Amostra e Definição das Variáveis}

O universo no qual o estudo está baseado é constituído pelos imóveis comerciais lançados e alugados em 2008, situados nas localidades do Município de São Paulo explicitadas em anexo (Figuras 1 e 2). O Município de São Paulo apresenta 96 distritos, de acordo com a Prefeitura (Figura 1), porém possui apenas 10 zonas comerciais, onde se encontra a maioria dos imóveis comerciais para locação situados em edifícios verticais de médio e alto padrão, sendo definidas de acordo com incorporadoras e gerenciadoras prediais como Bolsa de Imóveis do Estado de São Paulo e Jones Lang Lasalle (Figura 2). Estas localidades (distritos e zonas comerciais) são, portanto, definidas por meio de critérios distintos e sobrepõem-se geograficamente, conforme pode ser observado por meio da Figura 2, sendo que as 10 zonas comerciais situam-se ao longo de 16 distritos municipais. Como o apelo comercial dá-se, por vezes, com base em características de vizinhança pertencentes a distritos e também inerentes a zonas comerciais, a adoção de uma modelagem que consiga capturar as inter-relações destas características de forma cruzada faz sentido. 


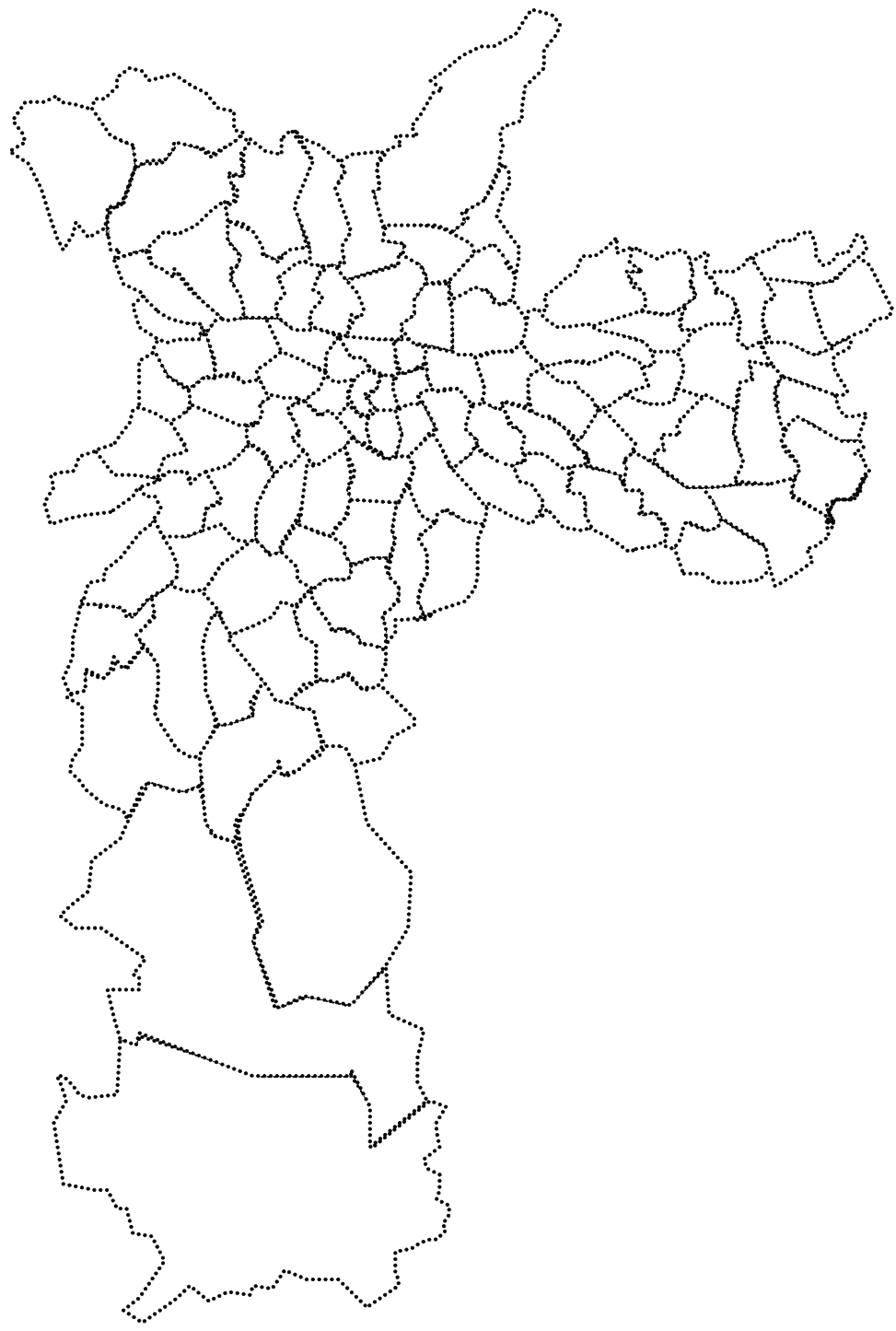

Fig. 1: O Município de São Paulo e seus 96 Distritos

Fonte: Site < www.prodam.sp.gov.br/svma/atlas_amb> Último acesso em 02 fev. 2010. 


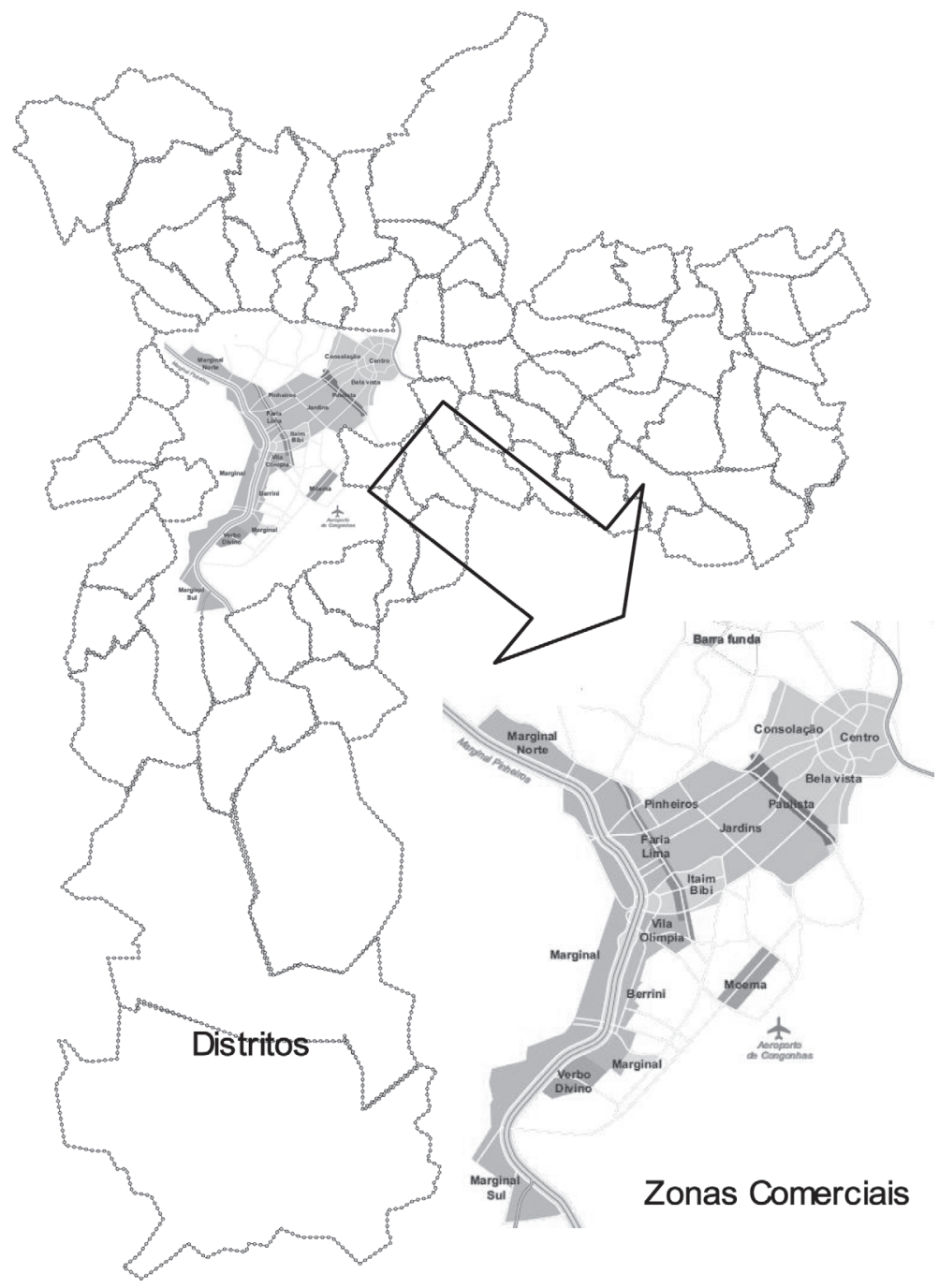

Fig. 2: Classificação Cruzada entre Distritos e Zonas Comerciais em São Paulo

Fonte: Site <http://www.joneslanglasalle.com.br/brazil/PT-BR/Pages/Home.aspx > Último acesso em 02 fev. 2010.

Este estudo é baseado numa amostra de 277 imóveis localizados em 15 distritos municipais e 10 zonas comerciais. A base original contava 332 imóveis em 16 distritos, porém, seguindo a mesma lógica proposta por Goldszmidt, Brito e Vasconcelos (2007) em relação aos critérios de exclusão de observações, foram eliminados imóveis que 
apresentam algum dado faltante em relação às variáveis explicativas ou à variável referente ao preço de aluguel. Além disto, os critérios buscaram evitar a indeterminação na alocação dos diferentes efeitos pela presença de menos de dois casos em cada fator. Assim, quando da montagem dos bancos de dados para a modelagem hierárquica, foram mantidas apenas as observações (neste caso, imóveis comerciais) que apresentaram duas ou mais observações provenientes de cada contexto de localidade (neste caso, determinado distrito e determinada zona comercial).

A Tabela 1 apresenta como a amostra de 277 imóveis está classificada (classificação cruzada) entre distritos e zonas comerciais. Os dados não refletem um desenho equilibrado em duas dimensões, como na análise clássica de variância, já que as dimensões amostrais por célula variam consideravelmente e a maioria das células da matriz está vazia. Ademais, algumas das variáveis preditoras são quantitativas e outras, qualitativas. Portanto, abordagens clássicas para a análise de dados em duas dimensões não são facilmente aplicadas.

Tabela 1-Classificação Cruzada dos Imóveis entre distritos e Zonas Comerciais

\begin{tabular}{|c|c|c|c|c|c|c|c|c|c|c|}
\hline \multicolumn{11}{|c|}{ Zona Comercial } \\
\hline Distrito & 1 & 2 & 3 & 4 & 5 & 6 & 7 & 8 & 9 & 10 \\
\hline 1 & 3 & & & & & & & & & \\
\hline 2 & 9 & 16 & 21 & & & & & & & \\
\hline 3 & & & 8 & 5 & & & & & & \\
\hline 4 & & & & 9 & 6 & & & & & \\
\hline 5 & & & & & 19 & & & & & \\
\hline 6 & & & & & 42 & & & & & \\
\hline 7 & & & & & & 13 & & & & \\
\hline 8 & & & & & & 55 & & & & \\
\hline 9 & & & & & & & 15 & 4 & & \\
\hline 10 & & & & & & & & 9 & 25 & \\
\hline 11 & & & & & & & & & 3 & \\
\hline 12 & & & & & & & & & 4 & \\
\hline 13 & & & & & & & & & & 3 \\
\hline 14 & & & & & & & & & & 3 \\
\hline 15 & & & & & & & & & & 5 \\
\hline
\end{tabular}

Por meio da Tabela 1 é possível verificar, por exemplo, que dos 13 imóveis localizados no distrito 3, 8 estão na zona 3 e 5 estão na zona 4. Da mesma forma, porém agora em coluna, é possível verificar que, dos 13 imóveis localizados na zona 8, 4 pertencem ao distrito 9 e 9 
ao distrito 10. A nomeação das variáveis intrínsecas e extrínsecas foi definida inicialmente por profissionais atuantes no mercado imobiliário (engenheiros, arquitetos e administradores que trabalham em empresas construtoras, incorporadoras e projetistas), por meio da aplicação de um levantamento autoadministrado, e tem por propósito a determinação, a priori, de algumas variáveis que compõem os preços de aluguel dos imóveis comerciais de São Paulo. Contudo, a relevância de cada variável será efetivamente definida quando da análise de significância de cada um de seus coeficientes nos modelos multinível. Com o levantamento prévio das variáveis hedônicas, da definição da amostra e da coleta dos dados, torna-se possível a elaboração dos modelos multinível com classificação cruzada.

O Quadro 1 apresenta os atributos intrínsecos e extrínsecos que foram nomeados pelos especialistas e que eventualmente podem explicar a formação dos preços de aluguel dos imóveis comerciais em São Paulo, com destaque para as variáveis dos imóveis, dos distritos e das zonas comerciais.

Quadro 1 - Atributos de Imóveis, Distritos e Zonas Comerciais

\begin{tabular}{lc}
\hline \multicolumn{1}{c}{ Atributo } & Nível \\
\hline Área Total do Edifício & Imóvel \\
Classificação do Edifício (A ou AA) & Imóvel \\
Número de Vagas de Estacionamento Interno por Escritório & Imóvel \\
Existência de Ar Condicionado Central no Edifício & Imóvel \\
Existência de Automação Predial no Edifício & Imóvel \\
Existência de Comunicação em Fibra Ótica no Edifício & Imóvel \\
Existência de Valet Park no Edifício & Imóvel \\
Existência de Piso Elevado nos Escritórios & Imóvel \\
Existência de Banheiro Privativo nos Escritórios & Imóvel \\
Existência de Heliponto no Edifício & Imóvel \\
Altura Relativa (Pavimento) do Escritório no Edifício & Imóvel \\
Existência de Restaurante ou Praça de Alimentação no Empreendimento & Imóvel \\
Proximidade de Estação de Metrô & Distrito \\
Proximidade de Shopping Center & Distrito \\
Distância ao Aeroporto de Congonhas & Distrito \\
Proximidade de Hospital Particular & Distrito \\
Proximidade de Parques e Áreas Verdes & Distrito \\
Renda do Distrito & Distrito \\
Indicador de Violência do Distrito & Distrito \\
Taxa de Vacância & Zona Comercial \\
\hline
\end{tabular}


Além dos atributos apresentados no Quadro 1 será incluída, no nível de imóvel, uma variável correspondente à distância de cada imóvel ao centro geográfico da zona comercial em que se situa. Esta inclusão baseia-se nas considerações elaboradas no trabalho de Fujita, Krugman e Mori (1999) sobre os sistemas de hierarquia urbana e regional.

Ressalta-se que a distância ao Aeroporto de Congonhas também poderia ser incluída no nível de imóvel, já que poderia incorporar a distância de cada imóvel à amenidade. Porém, como destacam alguns incorporadores, este atributo é utilizado como argumento para a locação, tendo em vista a caracterização do distrito e o seu posicionamento geográfico relativo ao aeroporto, independentemente do fato de um determinado imóvel estar mais ou menos distante de Congonhas frente a outro situado na mesma localidade.

A taxa de vacância, bastante discutida por Santos (2006), referese ao percentual de área útil disponível para locação em cada zona comercial, calculada em relação ao estoque total do mercado num determinado período. Trata-se, portanto, de um indicador da relação entre oferta e demanda de espaços para escritórios, num dado período, induzindo ou inibindo as decisões de investimento na expansão do estoque de áreas para locação comercial e permitindo a elaboração de prognósticos envolvendo tendências de excesso de oferta no mercado.

Com a nomeação dos atributos, podem ser definidas as variáveis explicativas que serão inseridas em cada um dos níveis hierárquicos. O Quadro 2 apresenta estas definições: 
Quadro 2 - Definições das Variáveis Hedônicas Explicativas de cada Nível

\begin{tabular}{|c|c|c|c|}
\hline Atributo & Variável & Definição & Nível Hierárquico \\
\hline Área Total do Edifício & АTOT & Área total em m² & Imóvel \\
\hline Classificação do Edifício (A ou AA) & CLASS & $\begin{array}{l}\text { Classificação: } \\
A A=1 ; A=0\end{array}$ & Imóvel \\
\hline $\begin{array}{l}\text { Número de Vagas de Estacionamento } \\
\text { Interno por Escritório }\end{array}$ & $\begin{array}{l}\text { VAGA1 } \\
\text { VAGA2 } \\
\text { VAGA3 }\end{array}$ & $\begin{array}{c}\text { Vagas na garagem: } \\
\text { Se VAGA1 }=0 ; \text { VAGA2 }=0 \text { e VAGA3 }=0: 01 \text { vaga } \\
\text { Se VAGA1 }=1 ; \text { VAGA2 }=0 \text { e VAGA3 }=0: 02 \text { vagas } \\
\text { Se VAGA } 1=0 ; \text { VAGA2 }=1 \text { e VAGA3 }=0: 03 \text { vagas } \\
\text { Se VAGA } 1=0 ; \text { VAGA2 }=0 \text { e VAGA3 }=1: \text { mais de } 03\end{array}$ & Imóvel \\
\hline $\begin{array}{l}\text { Existência de Ar Condicionado Central } \\
\text { no Edifício }\end{array}$ & ARCON & $\begin{array}{l}\text { Ar condicionado central: } \\
\operatorname{Sim}=1 ; \text { Não }=0\end{array}$ & Imóvel \\
\hline $\begin{array}{l}\text { Existência de Automação Predial } \\
\text { no Edifício }\end{array}$ & AUTOM & $\begin{array}{l}\text { Automação predial: } \\
\operatorname{Sim}=1 ; \text { Não }=0\end{array}$ & Imóvel \\
\hline $\begin{array}{l}\text { Existência de Comunicação em Fibra } \\
\text { Ótica no Edifício }\end{array}$ & COMFI & $\begin{array}{c}\text { Fibra ótica: } \\
\operatorname{Sim}=1 ; \text { Não }=0\end{array}$ & Imóvel \\
\hline Existência de Valet Park no Edifício & VALT & $\begin{array}{c}\text { Valet park: } \\
\operatorname{Sim}=1 ; \text { Não }=0\end{array}$ & Imóvel \\
\hline $\begin{array}{l}\text { Existência de Piso Elevado nos } \\
\text { Escritórios }\end{array}$ & PISEL & $\begin{array}{c}\text { Piso elevado: } \\
\text { Sim }=1 ; \text { Não }=0\end{array}$ & Imóvel \\
\hline $\begin{array}{l}\text { Existência de Banheiro Privativo nos } \\
\text { Escritórios }\end{array}$ & BANH & $\begin{array}{l}\text { Banheiro privativo: } \\
\operatorname{Sim}=1 ; \text { Não }=0\end{array}$ & Imóvel \\
\hline Existência de Heliponto no Edifício & HELI & $\begin{array}{c}\text { Heliponto: } \\
\operatorname{Sim}=1 ; \text { Não }=0\end{array}$ & Imóvel \\
\hline $\begin{array}{l}\text { Altura Relativa (Pavimento) do } \\
\text { Escritório no Edifício }\end{array}$ & ALTR & $\begin{array}{l}\text { Altura relativa do imóvel no edifício: } \\
\text { Metade Superior do Edifício }=1 ; \text { Não }=0\end{array}$ & Imóvel \\
\hline $\begin{array}{l}\text { Existência de Restaurante ou Praça de } \\
\text { Alimentação no Empreendimento }\end{array}$ & REST & $\begin{array}{l}\text { Restaurante ou praça de alimentação: } \\
\qquad \operatorname{Sim}=1 ; \text { Não }=0\end{array}$ & Imóvel \\
\hline $\begin{array}{l}\text { Distância do Imóvel ao Centro } \\
\text { Geográfico de sua Zona Comercial }\end{array}$ & CENTR & Em quilômetros & Imóvel \\
\hline Proximidade de Estação de Metrô & METR & $\begin{array}{l}\text { Estação de metrô no distrito: } \\
\qquad \operatorname{Sim}=1 ; \text { Não }=0\end{array}$ & Distrito \\
\hline Proximidade de Shopping Center & SHOPC & $\begin{array}{l}\text { Shopping Center no distrito: } \\
\text { Sim = 1; Não = } 0\end{array}$ & Distrito \\
\hline $\begin{array}{l}\text { Distância do Centro Geográfico do } \\
\text { Distrito ao Aeroporto de Congonhas }\end{array}$ & CONG & Em quilômetros & Distrito \\
\hline Proximidade de Hospital Particular & HOSP & $\begin{array}{l}\text { Hospital particular no distrito: } \\
\qquad \operatorname{Sim}=1 ; \text { Não }=0\end{array}$ & Distrito \\
\hline $\begin{array}{l}\text { Proximidade de Parques e Áreas } \\
\text { Verdes }\end{array}$ & PARQ & $\begin{array}{l}\text { Áreas verdes no distrito: } \\
\qquad \operatorname{Sim}=1 ; \text { Não }=0\end{array}$ & Distrito \\
\hline Renda do Distrito & REND & Renda média familiar em $\mathrm{R} \$$ & Distrito \\
\hline Indicador de Violência do Distrito & VIOL & $\begin{array}{l}\text { Taxa de mortalidade por causas externas (taxa por } \\
\text { cem mil habitantes) }\end{array}$ & Distrito \\
\hline Taxa de Vacância & VAC & $\begin{array}{c}\text { Percentual de área útil disponível para locação, } \\
\text { calculada em relação ao estoque total do mercado } \\
\text { numa determinada zona }\end{array}$ & Zona Comercial \\
\hline
\end{tabular}

Quando da elaboração da base de dados do nível 1, foram considerados apenas imóveis efetivamente alugados em 2008. Considerou-se, como preço de aluguel, os asking rents disponíveis no mercado por parte das empresas para a consecução da transação em cada ano que efetivamente ocorreu o aluguel. Os asking rents referem-se aos 
preços de aluguel ofertados e representam os valores que estão efetivamente disponíveis no mercado por parte das empresas, sendo, portanto, o montante que atrai os potenciais inquilinos e que identifica os atributos e a localização das propriedades.

Naturalmente, uma margem poderia estar incluída neste preço para permitir uma eventual negociação, mas como discutem Glascock, Jahanian e Sirmans (1990), há uma considerável estabilidade entre os preços de aluguel ofertados e transacionados quando da comparação entre imóveis comerciais, o que justifica a utilização dos asking rents como preços de equilíbrio, quando da efetivação do aluguel, para o presente estudo. Assim como para os preços de aluguel, os dados referentes às variáveis explicativas intrínsecas (preditoras do nível l) foram coletados a partir de anúncios de locação de imóveis comerciais em 2008, situados nas zonas comerciais apresentadas em anexo (Figura 2), publicados nos sites de imobiliárias e incorporadoras como CB Richard Ellis, Jones Lang LaSalle e Tishman Speyer.

A coleta de dados para cada variável correspondente aos atributos extrínsecos a serem inseridos no nível 2 da modelagem hierárquica, bem como para a variável relativa à distância entre o imóvel e o centro geográfico da zona comercial, foi elaborada de acordo com o explicitado por meio do Quadro 3 a seguir:

Quadro 3 - Forma de Coleta das Variáveis do Nível 2 e da Distância do Imóvel ao Centro da Zona Comercial

\begin{tabular}{|c|c|c|}
\hline Atributo & Variável & Fonte \\
\hline Proximidade de Estação de Metrô & METR & $\begin{array}{l}\text { site: http://www.metro.sp.gov.br } \\
\text { Último acesso em } 02 \text { abr. } 2009\end{array}$ \\
\hline Proximidade de Shopping Center & SHOPC & \\
\hline Proximidade de Hospital Particular & HOSP & \\
\hline Proximidade de Parques e Áreas Verdes & PARQ & $\begin{array}{c}\text { site: http://atlasambiental.prefeitura.sp.gov.br } \\
\text { Último acesso em } 30 \text { abr. } 2009\end{array}$ \\
\hline Renda do Distrito & REND & \\
\hline Indicador de Violência do Distrito & VIOL & \\
\hline $\begin{array}{l}\text { Distância do Centro Geográfico do Distrito ao } \\
\text { Aeroporto de Congonhas }\end{array}$ & CONG & site: http://maps.google.com.br \\
\hline $\begin{array}{l}\text { Distância do Imóvel ao Centro Geográfico de } \\
\text { sua Zona Comercial }\end{array}$ & CENTR & Último acesso em 23 abr. 2009 \\
\hline Taxa de Vacância & VAC & $\begin{array}{c}\text { site: http://www.joneslanglasalle.com.br/brazil } \\
\text { /PT-BR/Pages/Home.aspx } \\
\text { Último acesso em } 24 \text { mar. } 2009\end{array}$ \\
\hline
\end{tabular}


Com a definição e coleta das variáveis, pode ser elaborada a apresentação das estatísticas descritivas de cada uma delas, bem como dos modelos hierárquicos utilizado no presente estudo. A partir das Tabelas 2 e 3, observa-se que a média dos preços de aluguel dos imóveis ficou em torno de $\mathrm{R} \$ 93,35 / \mathrm{m}^{2}$. Por meio da amostra de 277 unidades comerciais, que a área total média dos edifícios que contêm estes imóveis é de $21.832,92 \mathrm{~m}^{2}$ e a maioria deles é classificada como A (214 unidades). Da amostra total, dois imóveis têm duas vagas na garagem, dez imóveis têm três vagas e o restante (265) oferece quatro ou mais vagas na garagem. Além disto, 275 oferecem ar condicionado central, 155 estão localizados em edifícios com automação predial, 41 têm comunicação em fibra ótica, 78 localizam-se em edifícios com serviço de valet park, 262 têm piso elevado, 264 oferecem banheiro privativo, 7 estão em edifícios com heliponto, 126 estão na metade superior do edifício e 76 estão em empreendimentos com praça de alimentação ou restaurantes. Por fim, a distância média dos imóveis aos centros geográficos de suas respectivas zonas comerciais é de 4,85 km. Em relação às características das variáveis que compõem o vetor de atributos extrínsecos, tem-se que os distritos considerados para este estudo apresentam renda média familiar de $\mathrm{R} \$ 3.433,93$ com taxa de mortalidade por causas externas de 54,55 por cem mil habitantes. Além disto, dos 15 distritos, 10 possuem estações de metrô, 10 têm Shopping Centers, 8 possuem hospitais particulares e 4 oferecem parques e áreas verdes em seu território. Ademais, a distância média dos centros geográficos distritais ao Aeroporto de Congonhas é de 9,61 km e a taxa de vacância média para as zonas em análise é de 7,95\%.

Tabela 2 - Estatísticas Descritivas - Variáveis Quantitativas

\begin{tabular}{lcccc}
\hline Variável & Média & Desvio-Padrão & Mínimo & Máximo \\
\hline Preço $\left(\mathrm{R} \$ / \mathrm{m}^{2}\right)$ & 93,35 & 29,37 & 32,00 & 215,62 \\
ATOT $\left(\mathrm{m}^{2}\right)$ & $21.832,92$ & $11.606,78$ & $8.770,00$ & $67.000,00$ \\
CENTR $(\mathrm{km})$ & 4,85 & 2,93 & 0,00 & 10,20 \\
REND $(\mathrm{R} \$)$ & $3.433,93$ & 970,75 & $1.366,00$ & $5.146,00$ \\
VIOL (por $10^{5}$ hab.) & 54,55 & 27,54 & 22,75 & 127,37 \\
CONG $(\mathrm{km})$ & 9,61 & 3,17 & 4,40 & 16,40 \\
VAC $(\%)$ & 7,95 & 4,31 & 3,00 & 15,00 \\
\hline
\end{tabular}


Tabela 3 - Estatísticas Descritivas - Variáveis Qualitativas

\begin{tabular}{|c|c|c|c|}
\hline Variável & Categoria & Frequência Absoluta & Frequência Relativa \\
\hline \multirow{2}{*}{ CLASS } & 0 & 214 & 77,3 \\
\hline & 1 & 63 & 22,7 \\
\hline \multirow{2}{*}{ VAGA1 } & 0 & 275 & 99,3 \\
\hline & 1 & 2 & 0,7 \\
\hline \multirow{2}{*}{ VAGA2 } & 0 & 267 & 96,4 \\
\hline & 1 & 10 & 3,6 \\
\hline \multirow{2}{*}{ VAGA3 } & 0 & 12 & 4,3 \\
\hline & 1 & 265 & 95,7 \\
\hline \multirow{2}{*}{ ARCON } & 0 & 2 & 0,7 \\
\hline & 1 & 275 & 99,3 \\
\hline \multirow{2}{*}{ AUTOM } & 0 & 122 & 44,0 \\
\hline & 1 & 155 & 56,0 \\
\hline \multirow{2}{*}{ COMFI } & 0 & 236 & 85,2 \\
\hline & 1 & 41 & 14,8 \\
\hline \multirow{2}{*}{ VALT } & 0 & 199 & 71,8 \\
\hline & 1 & 78 & 28,2 \\
\hline \multirow{2}{*}{ PISEL } & 0 & 15 & 5,4 \\
\hline & 1 & 262 & 94,6 \\
\hline \multirow{2}{*}{ BANH } & 0 & 13 & 4,7 \\
\hline & 1 & 264 & 95,3 \\
\hline \multirow{2}{*}{ HELI } & 0 & 270 & 97,5 \\
\hline & 1 & 7 & 2,5 \\
\hline \multirow{2}{*}{ ALTR } & 0 & 151 & 54,5 \\
\hline & 1 & 126 & 45,5 \\
\hline \multirow{2}{*}{ REST } & 0 & 201 & 72,6 \\
\hline & 1 & 76 & 27,4 \\
\hline \multirow{2}{*}{ METR } & 0 & 5 & 33,3 \\
\hline & 1 & 10 & 66,7 \\
\hline \multirow{2}{*}{ SHOPC } & 0 & 5 & 33,3 \\
\hline & 1 & 10 & 66,7 \\
\hline \multirow{2}{*}{ HOSP } & 0 & 7 & 46,7 \\
\hline & 1 & 8 & 53,3 \\
\hline \multirow{2}{*}{ PARQ } & 0 & 11 & 73,3 \\
\hline & 1 & 4 & 26,7 \\
\hline
\end{tabular}

\section{Resultados}

A Tabela 4 apresenta as fontes de variação para um coeficiente de nível $1 \pi_{\mathrm{pjk}}$, como especificado nas Equações (7) e (8):

Tabela 4 - Fontes de Variação para o Coeficiente do Nível $1 \pi_{\mathrm{pjk}}$

\begin{tabular}{|c|c|c|}
\hline Fonte de Variação & Contribuição & Graus de Liberdade \\
\hline (A) Média & $\theta_{\mathrm{p}}$ & 1 \\
\hline (B) Influência do Distrito & $\gamma_{\mathrm{p}} \mathrm{W}_{\mathrm{j}}$ & 1 \\
\hline (C) Efeitos Distritais Inexplicados & $\mathrm{b}_{\mathrm{p} 0 \mathrm{j}}$ & $J-2=13$ \\
\hline (D) Influência da Zona Comercial & $\beta_{\mathrm{p}} X_{\mathrm{k}}$ & 1 \\
\hline (E) Efeitos Inexplicados de Zonas Comerciais & $\mathrm{c}_{\mathrm{p} 0 \mathrm{k}}$ & $K-2=8$ \\
\hline (B) $x(D)$ & $\delta_{\mathrm{p}} Z_{\mathrm{jk}}$ & 1 \\
\hline (B) $x(E)$ & $\mathrm{C}_{\mathrm{p} 1 \mathrm{k}} \mathrm{W}_{\mathrm{j}}$ & $K-2=8$ \\
\hline (D) $x(C)$ & $\mathrm{b}_{\mathrm{p} 11} \mathrm{X}_{\mathrm{k}}$ & $J-2=13$ \\
\hline (C) $\times(E)$ & $d_{p j k}$ & $(J-2)(K-2)=104$ \\
\hline Total & & $\mathrm{JK}=150$ \\
\hline
\end{tabular}

Fonte: Baseado em Raudenbush e Bryk (2002). 
Seguindo a mesma lógica proposta por Raudenbush e Bryk (2002), e de acordo com a Tabela 4, há três fontes fundamentais de variação: variação entre distritos, variação entre zonas comerciais e variação "distrito-por-zona".

A variação entre distritos é dividida em um componente que é explicado pelos efeitos fixos do nível de distrito (B) e outro componente inexplicado (C). A variação entre zonas comerciais é, da mesma forma, dividida em um componente explicado pelos efeitos fixos do nível de zona comercial (D) e um componente inexplicado (E).

Cada um dos componentes de distrito interage com cada um dos componentes de zona comercial para formar fontes de variação "distrito-por-zona": um componente que é explicado pelos efeitos fixos [(B) x (D)], um componente que leva em consideração o fato de que o efeito da influência do nível distrito varia aleatoriamente sobre as zonas comerciais $[(\mathrm{B} \times(\mathrm{E})]$, um componente que considera que $\mathrm{o}$ efeito da influência do nível zona comercial varia aleatoriamente sobre os distritos [(D) x (C)], e um componente residual entre células não relacionado à influência $[(C) x(E)]$.

Os resultados empíricos para o modelo não condicional, considerando a restrição $\mathrm{d}_{0 \mathrm{jk}}=0$, são apresentados na Tabela 5 . A variação total nos preços de aluguel dos escritórios é decomposta em três componentes: $\tau_{\mathrm{b} 00}=0,140, \tau_{\mathrm{c} 00}=0,010$ e $\sigma^{2}=0,022$.

Tabela 5 - Parâmetro e Decomposição de Variância para o Modelo não Condicional

\begin{tabular}{|c|c|c|c|}
\hline Efeito Fixo & Coeficiente & Erro-Padrão & $t$ \\
\hline Intercepto do Modelo $\left(\theta_{0}\right)$ & $4,546^{* *}$ & 0,101 & 44,802 \\
\hline Efeito Aleatório & $\begin{array}{c}\text { Componente de } \\
\text { Variância }\end{array}$ & & \\
\hline Imóveis: $\operatorname{Var}\left(\mathrm{e}_{i \mathrm{ij}}\right)=\sigma^{2}$ & 0,022 & & \\
\hline Distritos: $\operatorname{Var}\left(\mathrm{b}_{00 \mathrm{j}}\right)=\tau_{\mathrm{b} 00}$ & 0,140 ** & & \\
\hline Zonas Comerciais: $\operatorname{Var}\left(\mathrm{C}_{00 k}\right)=\tau_{\mathrm{c} 00}$ & $0,010^{\star *}$ & & \\
\hline
\end{tabular}

$* * \mathrm{p}<0,01$.

Obs.: O desvio é 20,299. O número de parâmetros estimados é 4. 
De acordo com as Equações (4), (5) e (6), é possível calcular as três correlações:

$$
\begin{aligned}
& \rho_{\text {bcd }}=\frac{0,140+0,010}{0,140+0,010+0,022}=0,872 \\
& \rho_{b}=\frac{0,140}{0,140+0,010+0,022}=0,814 \\
& \rho_{c}=\frac{0,010}{0,140+0,010+0,022}=0,058
\end{aligned}
$$

Estas correlações indicam, ceteris paribus, que $81,4 \%$ da variação total nos preços de aluguel ocorrem entre distritos e 5,8\% entre zonas comerciais. Em outras palavras, mantidas todas as demais condições constantes, é possível inferir que $12,8 \%$ da variação total nos preços de aluguel dos imóveis associam-se com as diferenças existentes entre as características dos próprios imóveis.

Com o intuito de se avaliar a influência das variáveis preditoras do nível 1 no preço de aluguel dos imóveis comerciais, as variáveis não binárias foram centradas em suas respectivas médias. Após a inclusão de todas as variáveis preditoras no modelo do nível l, apenas as variáveis relativas à classificação do imóvel (CLASS) e à distância do imóvel ao centro geográfico de sua zona comercial (CENTR) foram identificadas como sendo significativas, a um nível de significância de $10 \%$, para influenciar os preços de locação. A equação estimada do nível l para o modelo condicional obedece ao que segue:

$$
\ln \left(\text { preço }_{i j k}=\pi_{0 j k}+\pi_{1 j k}(C L A S S)_{i j k}+\pi_{2 j k}(C E N T R)_{i j k}+e_{i j k}\right.
$$

O termo residual representa a variação dentro da célula nos preços de aluguel. O modelo HCM2 permite que sejam estudadas as inter-relações entre as hierarquias por meio das equações do nível 2. Seguindo os mesmos procedimentos metodológicos propostos por Raudenbush, Bryk, Cheong, Congdon e du Toit (2004) e Uyar e Brown (2007), especifica-se o termo de intercepto $\pi_{0 \mathrm{jk}}$ e os coeficientes de inclinação $\pi_{1 \mathrm{jk}}$ e $\pi_{2 \mathrm{jk}}$ provenientes da equação do nível 1 (10) como funções das variáveis dos distritos e das zonas comerciais. A versão final do modelo do nível 2 fica como segue: 


\section{Para o Intercepto:}

$$
\pi_{0 j k}=\theta_{0}+\beta_{01}(V A C)_{k}+\gamma_{01}(M E T R)_{j}+\gamma_{02}(C O N G)_{j}+\gamma_{03}(V I O L)_{j}+b_{00 j}+c_{00 k}
$$

Para a Variável CLASS:

$$
\pi_{1 j k}=\theta_{1}+\gamma_{11}(R E N D)_{j}
$$

\section{Para a Variável CENTR:}

$$
\pi_{2 j k}=\theta_{2}+\beta_{21}(V A C)_{k}
$$

A substituição das Equações (11), (12) e (13) na Equação (10) oferece o modelo completo. Os resultados empíricos deste modelo são

\begin{tabular}{|c|c|c|c|}
\hline Efeito Fixo & Coeficiente & Erro-Padrão & $\mathrm{t}$ \\
\hline \multicolumn{4}{|c|}{ Intercepto: $\pi_{0 j k}=\theta_{0}+\beta_{01}(V A C)_{k}+\gamma_{01}(\text { METR })_{j}+\gamma_{02}(C O N G)_{j}+\gamma_{03}(V I O L)_{j}$} \\
\hline Intercepto $\left(\theta_{0}\right)$ & $3,317^{\star *}$ & 0,579 & 5,728 \\
\hline Inclinação $\left(\beta_{01}\right)$ & $-0,014^{\star \star}$ & 0,005 & $-2,800$ \\
\hline Inclinação $\left(\gamma_{01}\right)$ & $0,357^{*}$ & 0,192 & 1,859 \\
\hline Inclinação $\left(\gamma_{02}\right)$ & $0,019^{*}$ & 0,007 & 2,714 \\
\hline Inclinação $\left(\gamma_{03}\right)$ & $-0,007^{\star}$ & 0,003 & $-2,333$ \\
\hline \multicolumn{4}{|c|}{ Inclinação para CLASS: $\pi_{1 j k}=\theta_{1}+\gamma_{11}(R E N D)_{j}$} \\
\hline Intercepto do Modelo $\left(\theta_{1}\right)$ & $0,139 * *$ & 0,015 & 9,266 \\
\hline Inclinação $\left(\gamma_{11}\right)$ & $1,2 \mathrm{E}-05^{\star \star}$ & $3,2 \mathrm{E}-06$ & 3,750 \\
\hline \multicolumn{4}{|c|}{ Inclinação para CENTR: $\pi_{2 j k}=\theta_{2}+\beta_{21}(V A C)_{k}$} \\
\hline Intercepto do Modelo $\left(\theta_{2}\right)$ & $-0,478^{\star \star}$ & 0,133 & $-3,594$ \\
\hline Inclinação $\left(\beta_{21}\right)$ & $-0,004 * *$ & 0,001 & $-4,000$ \\
\hline Efeito Aleatório & $\begin{array}{c}\text { Componente de } \\
\text { Variância }\end{array}$ & & \\
\hline Imóveis: $\operatorname{Var}\left(\mathrm{e}_{\mathrm{ijk}}\right)=\sigma^{2}$ & 0,010 & & \\
\hline Distritos: $\operatorname{Var}\left(\mathrm{b}_{00 \mathrm{j}}\right)=\tau_{\mathrm{b} 00}$ & $0,087^{\star \star}$ & & \\
\hline Zonas Comerciais: $\operatorname{Var}\left(\mathrm{C}_{00 k}\right)=\tau_{c 00}$ & $4,7 \mathrm{E}-05^{\star *}$ & & \\
\hline
\end{tabular}
apresentados na Tabela 6 a seguir.

Tabela 6 - Parâmetros e Decomposição de Variância para o Modelo Condicional

** $\mathrm{p}<0,01$.

${ }^{*} \mathrm{p}<0,10$.

Obs.: O desvio é -15,424. O número de parâmetros estimados é 13. 
De acordo com a Tabela 6 , a estimação da variância dentro da célula nos preços de aluguel $\left(\sigma^{2}\right)$ declinou de 0,022 para 0,010 . Este fato indica, de acordo com Uyar e Brown (2007), que as variáveis de nível incluídas na Equação (10) representam aproximadamente 55\% das diferenças remanescentes nos preços de aluguel dos imóveis situados no mesmo distrito e na mesma zona comercial.

A variância estimada $\tau_{\mathrm{b} 00}$ nos preços de aluguel entre distritos declinou de 0,140 para 0,087 , o que indica que, após levar em consideração o impacto das diferenças nas características dos escritórios e das zonas comerciais, as variáveis relacionadas aos distritos representam aproximadamente 38\% da variação remanescente nos preços médios de aluguel dos escritórios entre distritos. Finalmente, a variância estimada $\tau_{c 00}$ nos preços de aluguel entre zonas comerciais declinou de 0,010 para 4,7E-05, o que indica que, após a consideração do impacto das características dos imóveis e dos distritos, a taxa de vacância responde por todas as diferenças remanescentes nos preços médios de aluguel entre zonas comerciais, o que parece ser razoável, dado que as localidades em que os escritórios foram lançados neste estudo são relativamente homogêneas.

É possível notar que o desvio apresentou um declínio de 35,723 $(20,299$ - $(-15,424))$ e, como este apresenta uma distribuição Quiquadrado com 9 graus de liberdade (13 - 4), é estatisticamente significante (sig. $\chi^{2}<0,05$ ). Portanto, as variáveis de nível 1 e 2 incluídas no modelo condicional respondem por uma parcela relativamente significante das diferenças que ocorrem nos preços de aluguel entre imóveis localizados no mesmo distrito e na mesma zona comercial, e também entre aqueles situados em diferentes distritos e zonas comerciais.

Agora, a análise será voltada para a parte superior da Tabela 6 . Primeiramente, é possível notar que as variáveis VAC, METR, CONG e VIOL são significativas para diferenciar os preços médios de aluguel dos imóveis. Assim, imóveis localizados em zonas comerciais com menores taxas de vacância tendem a ser mais valorizados, pela própria existência de menor oferta frente à demanda existente. Da mesma forma, imóveis situados em distritos com estações de metrô e mais próximos do Aeroporto de Congonhas também são mais valorizados. Desta maneira, imóveis localizados em distritos com estações de metrô tendem a apresentar incrementos nos seus 
$\ln$ (preço), ceteris paribus, em comparação com aqueles situados em distritos sem esta amenidade urbana. Como esperado, quanto mais violento um distrito for (variável VIOL), menor será a média dos preços de aluguel dos escritórios.

As variáveis CLASS e CENTR referem-se à propriedade. A variável CLASS apresenta um coeficiente positivo e estatisticamente significante, indicando que, ceteris paribus, quando a categoria do edifício em que o imóvel encontra-se aumentar de A para AA, é de se esperar que o preço de aluguel seja incrementado. Já o oposto ocorre com a variável CENTR, dado o sinal negativo do coeficiente. Como a variável dependente é $\ln$ (preço), os coeficientes representam mudanças percentuais no preço escalonadas pelo logaritmo quando há uma mudança de uma unidade em uma determinada variável explicativa, o que faz com que, a cada quilômetro adicional de distância de um edifício ao centro da zona comercial, ceteris paribus, espera-se que os preços de aluguel dos escritórios sejam $38 \%$ menores $\left(\mathrm{e}^{-0,478}=\right.$ $0,62)$. Porém, se este imóvel mais distante estiver localizado em uma zona comercial com maior taxa de vacância, estima-se que seu preço seja 39\% menor quando a diferença na taxa de vacância for de $1 \%\left(\mathrm{e}^{[-0,478+(-0,004) \times(4,31)]}=0,61\right)$. Este fenômeno pode ser devido ao fato de que maiores níveis de disponibilidade em uma zona comercial, em termos de espaços a serem alugados, podem indicar o decréscimo de demanda proporcionalmente à oferta, resultando em preços de aluguel ainda menores para localidades com maiores taxas de vacância.

As inclinações $\pi_{1 \mathrm{jk}}$ e $\pi_{2 \mathrm{jk}}$ da equação do nível 1 permitem que sejam examinados os efeitos da interação entre hierarquias. Como o coeficiente da inclinação $\gamma_{11}$, referente à variável REND, é positivo e estatisticamente significante, imóveis situados em edifícios AA tendem a ter impactos mais exacerbados nos preços de aluguel se estiverem localizados em distritos de mais alta renda média familiar. Portanto, se uma propriedade AA estiver localizada em um distrito de mais alta renda, os preços de aluguel de seus escritórios tendem a ser $16 \%$ maiores quando a diferença na renda média familiar for de uma unidade $\left(\mathrm{e}^{[0,139+(1,2 \mathrm{E}-05) \times(970,75)]}=1,16\right)$, em que 970,75 é o desvio-padrão de REND, como pode ser observado por meio da Tabela 2). 
Como discutem Uyar e Brown (2007), assume-se que a relação entre a renda distrital e o preço de aluguel dos imóveis comerciais é a mesma entre zonas comerciais. Da mesma forma, assume-se que a relação entre a taxa de vacância das zonas comerciais e os preços de aluguel dos imóveis é a mesma entre distritos. Em outras palavras, não foram considerados, no modelo do nível 2 , os coeficientes $\mathrm{c}_{\mathrm{plk}} \mathrm{e}$ $b_{\mathrm{plj}}$, o que tornaria possível verificar se a relação entre renda distrital e preço de aluguel varia entre zonas comerciais e se a relação entre taxa de vacância e preço de aluguel varia entre distritos. Porém este novo modelo necessitaria de maiores graus de liberdade do que os existentes neste estudo.

Trabalhos como os de Gelfand, Ghosh, Knight e Sirmans (1998), Brown e Uyar (2004), e Uyar e Brown (2007) fizeram importantes contribuições para a definição de preços de imóveis por meio de modelagem multinível, porém com ênfase para o mercado imobiliário residencial. Todavia, corroboram a importância da inserção de variáveis de localidade e vizinhança em um nível específico do modelo. Enquanto Gelfand, Ghosh, Knight e Sirmans (1998) encontram maior representatividade da heterogeneidade da vizinhança para a formação de preços de imóveis residenciais, Brown e Uyar (2004) verificam a representatividade do tempo médio de deslocamento até o local de trabalho, considerado no nível 2 da modelagem, como atributo para a diferenciação de preços de unidades residenciais. Uyar e Brown (2007), por sua vez, aplicam um modelo HCM2 propriamente dito para verificar as influências e inter-relações de características sociodemográficas da vizinhança, como indicadores de renda e pobreza, e características de qualidade da educação das instituições de ensino situadas nas zonas escolares ao entorno das residências.

\section{Conclusões}

A utilização de modelos hierárquicos para o estudo de preços hedônicos no mercado imobiliário é ainda escassa. Muitos trabalhos fazem uso apenas de modelos de nível único, com a consideração de características intrínsecas e extrínsecas na mesma equação para o estudo dos preços dos imóveis. Entretanto, a modelagem multinível permite ao pesquisador analisar os percentuais de variância decorrentes de cada nível hierárquico, em uma perspectiva geográfica e espacial. Alguns estudos que utilizam a modelagem hierárquica de dois níveis 
no mercado imobiliário, em que o segundo nível representa os efeitos de vizinhança, de distritos ou de zonas comerciais sobre os preços das propriedades, têm encontrado diferenças significativas quando os modelos são comparados com os resultantes dos métodos tradicionais de nível único, uma vez que os modelos multinível consideram a interdependência entre as observações e apresentam variabilidade significativa entre observações provenientes de localidades diferentes. Ainda assim, são raros os trabalhos que estudam os preços de aluguel de imóveis comerciais em uma perspectiva hierárquica com classificação cruzada, mesmo que, em muitos casos, os próprios dados provenientes do mercado sejam inerentemente aninhados de forma cruzada. Ademais, mesmo que existam restrições quanto aos graus de liberdade e que ocorram limitações da técnica pela necessidade de estruturação dos dados de forma hierárquica, dados faltantes ou censurados (quando da existência de medidas repetidas no tempo) são permitidos, sem a necessidade de que o banco de dados seja balanceado entre os níveis (Uyar e Brown, 2007).

Outra contribuição do estudo refere-se à estimação de como as alterações nas características das propriedades alteram os preços entre os imóveis pertencentes em uma mesma localidade, assim como entre aqueles provenientes de localidades diferentes. Se o efeito distrital for maior, como é o caso do presente estudo, os impactos das diferenças das rendas médias familiares dos distritos nos preços de aluguel deve receber maior atenção. Se, por outro lado, as diferenças entre as propriedades explicassem a maior parte da variância, o foco na oferta e gestão de atributos intrínsecos e nas diferenças entre os imóveis deveria ser priorizado.

A terceira contribuição do presente estudo é a adição de variáveis preditoras em cada um dos níveis separadamente. Muitos trabalhos têm analisado a decomposição de variância entre os níveis hierárquicos, meramente determinando em qual nível ocorre a maior parcela de variabilidade, porém não se preocupando com as influências decorrentes da inserção de uma ou mais variáveis em cada um dois níveis (Rumelt, 1991). De acordo com Short, Ketchen Jr., Bennett e du Toit (2006), aplicações com modelos multinível oferecem novas possibilidades de se testar hipóteses mais complicadas, sem o risco de violação das premissas inerentes a outras técnicas. 
Outras considerações podem ser adotadas quando do estudo do mercado imobiliário. A inclusão de novas variáveis explicativas nos níveis l e 2 e mesmo a investigação de eventuais diferenças intermunicipais, em uma perspectiva estática ou temporal, podem ser utilizadas para se determinarem novas estratégias e se elaborarem novos modelos, com o objetivo de se aprofundar o entendimento dos mecanismos de formação de preços no mercado imobiliário.

\section{Referências}

Aitkin, M.; Anderson, D.; Hinde, J. (1981) Statistical modelling of data on teaching styles (with discussion). Journal of the Royal Statistical Society, Series A, v. 144, p. 148-161.

Aitkin, M.; Longford, N. (1986) Statistical modelling in school effectiveness studies (with discussion). Journal of the Royal Statistical Society, Series A, v. 149, p. 1-43.

Anselin, L.; Gracia, N. L. (2008) Errors in variables and spatial effects in hedonic house price models of ambient air quality. Empirical Economics, v. 34, n. 1, p. 5-34.

Aryeetey-Attoh, S. (1982) An analysis of household valuations and preference structures in Rio de Janeiro, Brazil. Growth and Change, v. 3, n. 2, p. 183-198.

Barbosa, E. P.; Bidurin, C. P. (1991) Seleção de modelos de regressão para predição via validação cruzada: uma aplicação na avaliação de imóveis. Revista Brasileira de Estatística, v. 52, n. 197/198, p. 105-120.

Bartik, T. J. (1987) The estimation of demand parameters in hedonic price models. Journal of Political Economy, v. 95, n. 1, p. 81-88.

Bible, D. S.; Hsieh, C. (2001) Gated communities and residential property values. The Appraisal Journal, v. 69 , n. 2 , p. $140-145$.

Bottai, M.; Salvati, N.; Orsini, N. (2006) Multilevel models for analyzing people's daily movement behavior. Journal of Geographical Systems, v. 8, n. 1, p. 97-108.

Brown, K. H.; Uyar, B. (2004) A hierarchical linear model approach for assessing the effects of house and neighborhood characteristics on housing prices. Journal of Real Estate Practice and Education, v. 7, n. 1, p. 15-23.

Cardoso, A. R. (2000) Wage differentials across firms: an application of multilevel modelling. Journal of Applied Econometrics, v. 15, n. 4, p. 343-354.

Chang, S.; Singh, H. (2000) Corporate and industry effects on business unit competitive position. Strategic Management Journal, v. 21, n. 7, p. 739-752.

Chattopadhyay, S. (2000) The effectiveness of McFadden's nested logit model in valuing amenity improvements. Regional Science and Urban Economics, v. 30, n. 1, p. 23-43.

Chau, K. W.; Ma, V. S. M.; Ho, D. C. W. (2001) The pricing of 'luckiness' in the apartment market. Journal of Real Estate Literature, v. 9, n. 1, p. 31-40.

Cheshire, P.; Sheppard, S. (1998) Estimating the demand for housing, land, and neighborhood characteristics. Oxford Bulletin of Economics and Statistics, v. 60, n. 3, p. 357-382.

Christmann, P.; Day, D. L.; Yip, G. S. (1999) The relative influence of country conditions, industry structure and business strategy on MNC subsidiary performance. Journal of International Management, v. 5, n. 4, p. 241-265. 
Clark, D. E.; Herrin, W. E. (2000) The impact of public school attributes on home sale prices in California. Growth and Change, v. 31, n. 3, p. 385-407.

Collins, J. M. (1990) A market performance comparison of U.S. firms active in domestic, developed, and developing countries. Journal of International Business Studies, v. 21, n. 2, p. 271-287.

Dantas, R. A.; Cordeiro, G. M. (1988) Uma nova metodologia para a avaliação de imóveis utilizando modelos lineares generalizados. Revista Brasileira de Estatística, v. 49, n. 191, p. 27-46.

Downes, T. A.; Zabel, J. E. (2002) The impact of school characteristics on housing prices: Chicago 1987-1991. Journal of Urban Economics, v. 52, n. 1, p. 1-25.

Draper, D. (1995) Inference and hierarchical modeling in the social sciences. Journal of Educational and Behavioral Statistics, v. 20, n.2, p. 115-147.

Ekeland, I.; Heckman, J.; Nesheim, L. (2002) Identifying hedonic models. American Economic Review, v. 92 , n. 2, p. 304-309.

Fávero, L. P. L.; Belfiore, P. P. Attributes, neighborhood and time effects on residential property prices in São Paulo, Brazil: a multilevel approach. $I n$ : $50^{\text {th }}$ ANNUAL MEETING OF THE ACADEMY OF INTERNATIONAL BUSINESS, 2008, Milan. Anais do Congresso. Milan: 50 ${ }^{\text {th }}$ AIB, 2008. 1 CD-ROM.

Fávero, L. P. L.; Belfiore, P. P.; Lima, G. A. S. F. (2008) Modelos de precificação hedônica de imóveis residenciais na Região Metropolitana de São Paulo: uma abordagem sob as perspectivas da demanda e da oferta. Estudos Econômicos, v. 38, n. 1, p. 73-96.

Figlio, D.; Lucas, M. (2004) What's in a grade? School report cards and housing prices. American Economic Review, v. 94, n. 3, p. 591-604.

Fujita, M.; Krugman, P.; Mori, T. (1999) On the evolution of hierarchical urban systems. European Economic Review, v. 43, n. 2, p. 209-251.

Garner, C. L., Raudenbush, S. (1991) Neighborhood effects on educational attainment: a multilevel analysis. Sociology of Education, v. 64, n. 4, p. 251-262.

Gelfand, A. E.; Ghosh, S. K.; Knight, J. R.; Sirmans, C. F. (1998) Spatio-temporal modeling of residential sales data. Journal of Business \& Economic Statistics, v. 16, n. 3, p. 312-321.

Gelman, A. (2006) Multilevel (hierarchical) modeling: what it can and cannot do. Technometrics, v. 48 , n. 3, p. 432-435.

Glascock, J.; Jahanian, S.; Sirmans, C. (1990) An analysis of office market rents: some empirical evidence. AREUEA Journal, v. 18, n. 1, p. 105-119.

Goldstein, H. (2003) Multilevel statistical models. London: Arnold.

Goldszmidt, R. G.; Brito, L. A.; Vasconcelos, F. C. O efeito país sobre o desempenho da firma: uma abordagem multinível. In: ENCONTRO DE ESTUDOS EM ESTRATÉGIA, 2007, São Paulo. Anais do Congresso. São Paulo: 3 E’s, 2007. 1 CD-ROM.

González, M. A. S.; Formoso, C. T. (1994) Especificação de modelos de preços hedônicos para locação residencial em Porto Alegre. Cadernos IPPUR / UFRJ, v. 8, n. 1, p. 59-72.

Goodman, A.; Thibodeau, T. G. (1998) Housing market segmentation. Journal of Housing Economics, v. 7, n. 2, p. 121-143.

Hawawini, G.; Subramanian, V.; Verdin, P. (2004) The home country in the age of globalization: how much does it matter for firm performance? Journal of World Business, v. 39, n. 2, p. 121-135.

Hermann, B. M. (2005) Mercado imobiliário e amenidades urbanas: a view through the window. Estudos Econômicos, v. 35, n. 2, p. 237-269.

Jones, K.; Bullen, N. (1994) Contextual models of urban house prices: a comparison of fixed-and randomcoefficient models developed by expansion. Economic Geography, v. 70, n. 3, p. 252-272. 
Jones, K.; Johnston. R. J.; Pattie, C. J. (1992) People, places and regions: exploring the use of multilevel modelling in the analysis of electoral data. British Journal of Political Science, v. 22, n. 3, p. 343-380.

Kahane, L. H. (2001) Team and player effects on NHL player salaries: a hierarchical linear model approach. Applied Economics Letters, v. 8, n. 9, p. 629-632.

Lee, B. H. (2003) Using hierarchical linear modeling to illustrate industry and group effects on organizational commitment in a sales context. Journal of Managerial Issues, v. 15, n. 3, p. 353-368.

Leeuw, F. (1993) A price index for new multifamily housing. Bureau of Economic Research, v. 73, n. 2, p. 33-42.

Leishman, C. (2001) House building and product differentiation: an hedonic price approach. Journal of Housing and the Built Environment, v. 16, n. 2, p. 131-152.

Makino, S.; Beamish, P. W.; Zhao, N. B. (2004) The characteristics and performance of Japanese FDI in less developed and developed countries. Journal of World Business, v. 39, n. 4, p. 377-392.

Makino, S.; Isobe, T.; Chan, C. (2004) Does country matter? Strategic Management Journal, v. 25, n. 10, p. 1027-1043.

Mauri, A. J.; Michaels, M. P. (1998) Firm and industry effects within strategic management: an empirical examination. Strategic Management Journal, v. 19, n. 3, p. 211-219.

McFadden, D. Modelling the choice of residential location. In: Karlqvist, A.; Lundqvist, L.; Snickers, F.; Weibull, J. W. (Ed.) (1978) Spatial interaction theory and planning models. New York: North-Holland.

Megbolugbe, I. F. (1989) A hedonic index model: the housing market of Jos, Nigeria. Urban Studies, v. 26, n. 5 , p. $486-494$.

Mills, E. (1992) Office rent determinants in the Chicago area. AREUEA Journal, v. 20, n. 2, p. 273-287.

Mithas, S.; Ramasubbu, N.; Krishnan, M. S.; Fornell, C. (2007) Designing web sites for customer loyalty across business domains: a multilevel analysis. Journal of Management Information Systems, v. 23, n. 3, p. 97-127.

Moreira, A. L. (1997) Princípio de engenharia de avaliações. São Paulo: Pini.

Nechyba, T. J.; Strauss, R. P. (1998) Community choice and local public services: a discrete choice approach. Regional Science and Urban Economics, v. 28, n. 1, p. 51-73.

O'Connell, A. A.; McCoach, D. B. (Ed.) (2008) Multilevel modeling of educational data. Charlotte: Information Age Publishing.

Osborne, J. W. (2010) Advantages of hierarchical modeling. Practical Assessment, Research \& Evaluation, v. 7, n. 1, 2000. Disponível em: $<$ http://pareonline.net/getvn.asp? $=7 \& \mathrm{n}=1>$ Acesso em: 22 jan.

Palmquist, R. B. (1984) Estimating the demand for the characteristics of housing. The Review of Economics and Statistics, v. 66, n. 3, p. 394-404.

Paterson, R. W.; Boyle, K. J. (2002) Out of sight, out of mind? Using GIS to incorporate visibility in hedonic property value models. Land Economics, v. 78, n. 3, p. 417-425.

Price, P. N.; Nero, A. V.; Gelman, A. (1996) Bayesian prediction of mean indoor radon concentrations for Minnesota counties. Health Physics, v. 71, n. 6, p. 922-936.

Quigley, J. M. (1985) Consumer choice of dwelling, neighborhood and public services. Regional Science and Urban Economics, v. 15, n. 1, p. 41-63.

Raudenbush, S. (1993) A crossed random effects model for unbalanced data with applications in crosssectional and longitudinal research. Journal of Educational Statistics, v. 18, n. 4, p. 321-349.

Raudenbush, S.; Bryk, A. (2002) Hierarchical linear models: applications and data analysis methods. Thousand Oaks: Sage Publications. 
(1986) A hierarchical model for studying school effects. Sociology of Education, v. 59, n. 1, p. 1-17.

Raudenbush, S.; Bryk, A.; Cheong, Y. F.; Congdon, R.; du Toit, M. (2004) HLM 6: Hierarchical linear and nonlinear modeling. Lincolnwood: Scientific Software International, Inc.

Rengers, M.; Velthuis, O. (2002) Determinants of prices for contemporary arts in Dutch galleries, 1992 1998. Journal of Cultural Economics, v. 26, n. 1, p. 1-28.

Rosen, S. (1974) Hedonic prices and implicit markets: production differentiation in pure competition. Journal of Political Economy, v. 82, n. 1, p. 34-55.

Ruefli, T. W.; Wiggins, R. R. (2003) Industry, corporate and segment effects and business performance: a non-parametric approach. Strategic Management Journal, v. 24, n. 9, p. 861-879.

Rumberger, R. W.; Thomas, S. L. (1993) The economic returns to college major, quality and performance: a multi-level analysis of recent graduates. Economics of Education Review, v. 12, n. 1, p. 1-19.

Rumelt, R. P. (1991) How much does industry matter? Strategic Management Journal, v. 12, n. 3, p. 167-185.

Santos, A. R. O desenvolvimento do mercado de edifícios de escritórios para locação na Cidade de São Paulo impulsionado pela securitização, 2006. 147 f. Dissertação (Mestrado em Engenharia Civil) - Escola Politécnica, Universidade de São Paulo.

Schmalensee, R. (1985) Do markets differ much? American Economic Review, v. 75, n. 3, p. 341351.

Short, J. C. ; Ketchen Jr., D. J.; Bennett, N.; du Toit. M. (2006) An examination of firm, industry, and time effects on performance using random coefficients modeling. Organizational Research $\mathrm{Me}$ thods, v. 9, n. 3, p. 259-284.

Short, J. C.; Ketchen Jr.; D. J.; Palmer, T. B.; Hult, G. T. (2007) Firm, strategic group, and industry influences on performance. Strategic Management Journal, v. 28, n. 2, p. 147-167.

Sibthorp, J.; Witter, E.; Wells, M.; Ellis, G.; Voelkl, J. (2004) Hierarchical linear modeling in park, recreation, and tourism research. Journal of Leisure Research, v. 36, n. 1, p. 89-100.

Simons, R. A.; Jaouhari, A. E. (2004) The effect of freight railroad tracks and train activity on residential property values. The Appraisal Journal, v. 72, n. 3, p. 223-233.

Soto, J. L.; Morera, M. C. (2005) Modelos jerárquicos lineales. Madrid: La Muralla.

Strand, J.; Vagnes, M. (2001) The relationship between property values and railroad proximity: a study based on hedonic prices and real estate brokers' appraisals. Transportation, v. 28, n. 2, p. 137-156.

Uyar, B.; Brown, K. H. (2007) Neighborhood affluence, school-achievement scores, and housing prices: cross-classified hierarchies and HLM. Journal of Housing Research, v. 16, n. 2, p. 97-116.

$\mathrm{Xu}, \mathrm{T}$. (2008) Heterogeneity in housing attribute prices: a study of the interaction behaviour between property specifics, location coordinates and buyers' characteristics. International Journal of Housing Markets and Analysis, v. 1, n. 2, p. 166- 181.

Yinger, J.; Bloom, H. S.; Borsch-Supan, A.; Ladd, H. F. (1988) Property taxes and house values. London: Academic Press. 